\title{
KAJIAN SEMIOTIKA MANTRA BANJAR
}

\author{
Jamilah $^{1)}$, Fajarika Ramadania ${ }^{2)}$ \\ Program Studi Pendidikan Bahasa dan Sastra Indonesia \\ Universitas Terbuka Banjarmasin, STKIP PGRI Banjarmasin \\ jamilah-bjm@ecampus.ut.ac.id, framadania@stkipbjm.ac.id
}

\begin{abstract}
This research was conducted by using qualitative research approach and descriptive method, that is solving problem by collecting data, compiling data, classifying data, analyzing data and reporting research result. The data in this research is collected by library method and interview then the data is analyzed by using descriptive analysis. Based on the description of data analysis that has been presented in the study of Banjar spell seismotics, obtained the conclusion of 12 types and the form Banjar of spell pattern. This study deals with the study of the physical form, type, and function of the Banjar mantra.
\end{abstract}

Key Word: collecting data, type, banjar mantra

\section{ABSTRAK}

Penelitian ini berkaitan dengan kajian bentuk fisik, jenis, dan fungsi mantra Banjar. Penelitian ini dilaksanakan dengan mengunakan pendekatan penelitian kualitatif dan metode deskriptif, yaitu memecahkan masalah dengan mengumpulkan data, menyusun data, mengklasifikasikan data, menganalisis data dan melaporkan hasil penelitian. Datadata dalam penelitian ini dikumpulkan dengan metode kepustakaan dan wawancara yang kemudian data tersebut dianalisis dengan mengunakan analisis deskriptif. Berdasarkan deskripsi pada analisis data yang telah dipaparkan dalam kajian seismotika mantra banjar, diperoleh kesimpulan sebanyak 12 jenis dan bentuk pola mantra banjar.

Kata Kunci: bentuk fisik, bentuk pola, mantra banjar

\section{PENDAHULUAN}

Sebagai salah satu produk budaya, seni memiliki berbagai bentuk pengungkapan yang pada prinsipnya bertujuan untuk mengkomunikasikan pikiran dan perasaan masyarakat yang tumbuh dan bekembang dari waktu ke waktu. Salah satu bentuk pengungkapan seni sebagai produk budaya adalah mantra. Hampir dapat dipastikan setiap suku di tanah air memiliki puisi lama berjenis mantra.

Kalimantan Selatan adalah
provinsi yang mayoritas
penduduknya suku Banjar atau yang
sering disebut orang Banjar. Salah
satu dari sekian banyak bahasa
daerah yang ada di Indonesia adalah

bahasa Banjar, bahasa ini digunakan sebagai bahasa pergaulan sehari-hari dalam kalangan penduduk daerah provinsi Kalimantan Selatan. Daerah Banjar sama dengan daerah lainnya juga mempunyai peradaban dan kebudayaan, salah satunya adalah sastra daerah Banjar, termasuk didalamnya Mantra Banjar . Menurut pengertian yang sederhana mantra Banjar adalah mantra berbahasa Banjar. Etnis Banjar di Kalsel menyebutnya bacaan atau kata (Sulistyowati dan Ganie, 2013: 42). Mantra diyakini sebagai bentuk sastra lisan paling tua yang dimiliki oleh masyarakat Melayu. Mantra adalah salah satu jenis puisi lama Melayu yang diyakini mengandung 
kekuatan ghaib dan kesaktian. Oleh karena itu, mantra biasanya diajarkan oleh orang yang mempunyai kekuatan gaib dan kesaktian yang disebut dukun, bomoh, atau pawang (Sugiarto, 2015: 91).

Mantra bagi masyarakat Banjar sangat beraneka ragam, setidaknya ada 14 ragam/jenis mantra Banjar, yakni kariau (panggilan), kasumbi (ajian kekuatan), mamang (panggilan roh leluhur), pakasih (kasih), pambanci (sumber kebencian), pambungkam (bungkam), panangkal (pencegah), panawar (penawar), panulak (menolak), panyangga (penahan), papikat (pemikat), pikaras (mengeraskan/meneguhkan), pirunduk (penakluk), sumpah sarapah (sumpah serapah) (Ganie dalam Sulistyowati dan Ganie, 2013: 47).

Seiring dengan kemajuan zaman yang sudah berkembang pada era globalisasi, mantra Banjar sudah mulai tergeser keberadaannya dan secara perlahan mulai dilupakan. Namun pada sebagian masyarakatnya mantra masih memiliki posisi dan peranan penting dalam menjalani kehidupan. Kehadiran mantra itu sendiri berpangkal pada kepercayaan masyarakat pendukung di dalamnya yang memunculkan fenomena yang semakin kompleks dijaman sekarang. Sejumlah penilaian, sikap, dan perlakuan masyarakat terhadap mantra semakin berkembang. Ada sebagian masyarakat yang begitu mengikatkan secara penuh maupun sebagian dirinya terhadap mantra dalam kepentingan hidupnya. Sebagian masyarakat lainnya secara langsung atau tidak langsung menolak kehadiran mantra dengan pertimbangan bahwa menerima mantra berarti melakukan perbuatan syirik. Pada bagian masyarakat yang disebutkan pertama dapat digolongkan ke dalam masyarakat penghayat atau pendukung mantra, sedangkan bagian masyarakat yang lainnya digolongkan ke dalam masyarakat bukan penghayat mantra.

Bagi masyarakat penghayat mantra, kegiatan sehari-hari kerap kali diwarnai dengan pembacaan mantra demi keberhasilan dalam mencapai maksud atau tujuan yang sesuai dengan fungsi dari mantra tersebut. Mantra diterima oleh masyarakat penghayatnya sebagai kebutuhan penunjang setelah kehidupan agamanya dijalani secara sungguh-sungguh. Adanya kebutuhan terhadap mantra sebagai warna yang menghiasi kehidupan sehari-hari. Kegiatan yang tidak terlepas kepada keadaan alam dan mata pencaharian, menghasilkan tiga kelompok besar sehubungan dengan penggunaan mantra, yaitu mantra yang digunakan untuk perlindungan, kekuatan, dan pengobatan.

Mantra Banjar merupakan sebuah kearifan lokal yang dimiliki oleh masyarakat Kalimantan Selatan sebagai bagian dari budaya. Mantra dapat memberikan gambaran luas tentang pola dan macam kehidupan masyarakat pendukungnya. Sebagai bagian dari budaya mantra merupakan suatu keberhasilan karya cipta sastra yang harus diwariskan dari generasi kegenerasi.

Keberadaan mantra Banjar saat ini sangat terancam keberadaannya. Menurut Saberi (2010:2) sejak agama islam dijadikan sebagai agama resmi di Kerajaan Banjar pada tahun 1526, semua produk budaya lama yang berbau animisme mulai tergusur dari ranah budaya lokal, digantikan dengan produk budaya yang selaras dengan hukum-hukum 
syar'i yang berlaku dalam agama Islam.

\section{METODE PENELITIAN}

Jenis yang digunakan dalam penelitian ini adalah pendekatan kualitatif. Pendekatan kualitatif sengaja dipilih agar peneliti dapat memecahkan masalah dengan mengumpulkan data, menganalisis data, dan melaporkan hasil secara apa adanya sesuai dengan data yang diperoleh dalam penelitian. Adapun jenis penelitian yang digunakan adalah jenis penelitian analisis isi/studi dokumentasi dengan cara menganalisis data hasil dari wawancara. Jenis penelitian analisis isi/studi dokumentasi mantra Banjar dilakukan disertai penghayatan secara langsung, dan pemahaman arti secara rasional sehingga diperoleh hasil yang mendalam ini digunakan karena dapat mempermudah dalam melakukan analisa terhadap data yang diperoleh dari hasil wawancara dengan narasumber.

Pengumpulan data ini dilakukan dengan teknik mewawancarai narasumber, dan studi dokumentasi atau kajian kepustakaan (kajian teks). Prosedur ini dilakukan disertai penghayatan secara langsung, dan pemahaman arti secara rasional sehingga diperoleh hasil yang mendalam. Dalam strategi pengumpulan data dilakukan dengan langkah-langkah sebagai berikut :

1. Pengumpulan dokumen;

2. Pengamatan;

3. Wawancara tidak terstruktur (bersifat informal);

4. Merekam wawancara; dan

5. Mencatat hasil wawancara.

Karya sastra merupakan struktur yang kompleks, maka untuk memahaminya perlu adanya analisis, yaitu menguraikan bagian-bagian atau unsur-unsurnya Suruso (2009:64). Penelitian ini dilakukan dengan tujuan untuk mendeskripsikan data-data kualitatif yang dapat dikumpulkan dari hasil wawancara dengan narasumber yang menyangkut karakteristik mantra Banjar berdasarkan bentuk, jenis dan fungsi mantra Banjar tersebut. Datadata kualitatif yang dimaksud dideskripsikan dengan memanfaatkan seperangkat teori yang relevan sebagai panduan atau ancangan kajiannya dalam pelaksanaan penelitian secara keseluruhan. Data dalam penelitian ini dianalis dengan menggunakan 3 prinsip analisis, yaitu :
a. Pemahaman arti
secara mendalam;
b. Analisis isi;
c. Analisis berulang sesuai dengan keperluan penelitian;

Analisis data dilakukan dengan langkah-langkah sebagai berikut.

a. Melakukan identifikasi, pada tahap ini peneliti membaca dan mengamati secara kritis semua mantra Banjar yang berhasil dikumpulkan sebagai sumber data dalam penelitian ini. Identifikasi dilakukan dalam rangka memperoleh penghayatan dan pemahaman terhadap mantra Banjar.

b. Melakukan klasifikasi, pada tahap ini peneliti mengelompokan data sesuai dengan jenisnya berdasarkan rumusan masalah, yakni bentuk, jenis dan fungsi mantra Banjar.

c. Melakukan rekontruksi, pada tahap ini peneliti melakukan berbagai upaya untuk memahami lebih luas tentang 
karakteristik bentuk, jenis, dan fungsi mantra Banjar. Tujuan kegiatan ini adalah untuk memahami konsep, menelusuri, dan memahami latar belakang ide konsepnya.

d. Melakukan simpulan, pada tahap ini peneliti melakukan perumusan simpulan data sementara dan kemudian melakukan verifikasi berulangulang untuk memperoleh kesimpulan akhir tentang karakteristik bentuk, jenis, dan fungsi mantra Banjar.

Instrumen dalam penelitian ini adalah peneliti sendiri (human instrument), yaitu sebagai instrumen kunci dengan bantuan instrumen pendukung berupa table data. Penelitian ini juga menggunakan kriteria-kriteria sebagai perangkat lunak untuk memudahkan dalam pengambilan data dan analisis data. Kriteria yang digunakan adalah untuk menentukan bentuk fisik, jenis, dan fungsi mantra Banjar.

Dalam menentukan bentuk fisik, jenis, dan fungsi mantra Banjar peneliti berpatokan pada teori yang dikemukakan Sulistyowati dan Ganie (2013). Bentuk fisik mantra Banjar yang dikemukakan Sulistyowati dan Ganie (2013) diantaranya : mantra Banjar bentuk bebas dan mantra Banjar bentuk terikat. Untuk jenis mantra Banjar diantaranya : (a) Kariau, (b) Kasumbi, (c) Mamang, (d) Pakasih, (e) Pambanci, (f) Pambungkam, (g) Panawar, (h) Panulak, (i) Papikat, (j) Pikaras, (k) Pirunduk, (1) Sumpah sarapah.

Dengan kriteria tersebut peneliti dapat menganalisis setiap bentuk, jenis dan fungsi mantra Banjar yang akan diteliti.

Tabel 1. Variabel Penelitian

\begin{tabular}{|c|c|c|c|}
\hline No & Variabel & Sub Variabel & Kode \\
\hline \multirow[t]{5}{*}{1} & Bentuk & 1. Mantra Banjar Bentuk Bebas & 1. MBBB \\
\hline & & 2. Mantra Banjar Bentuk Terikat 1 & $\begin{array}{l}\text { 2. MBBT } \\
1\end{array}$ \\
\hline & & 3. Mantra Banjar Bentuk Terikat 2 & $\begin{array}{l}\text { 3. MBBT } \\
2\end{array}$ \\
\hline & & 4. Mantra Banjar Bentuk Terikat 3 & $\begin{array}{l}\text { 4. MBBT } \\
3\end{array}$ \\
\hline & & 5. Mantra Banjar Bentuk Terikat 4 & $\begin{array}{l}\text { 5. MBBT } \\
4\end{array}$ \\
\hline \multirow[t]{12}{*}{2} & Jenis & 1. Kariau & 1. $\mathrm{Kr}$ \\
\hline & & 2. Kasumbi & 2. Ks \\
\hline & & 3. Mamang & 3. $\mathrm{Mm}$ \\
\hline & & 4. Pakasih & 4. Ps \\
\hline & & 5. Pambanci & 5. $\mathrm{Pb}$ \\
\hline & & 6. Pambungkam & 6. Pm \\
\hline & & 7. Panawar & 7. $\mathrm{Pn}$ \\
\hline & & 8. Panulak & 8. $\mathrm{Pl}$ \\
\hline & & 9. Papikat & 9. $\mathrm{Pk}$ \\
\hline & & 10. Pikaras & 10. $\operatorname{Pr}$ \\
\hline & & 11. Pirunduk & 11. $\mathrm{Pd}$ \\
\hline & & 12. Sumpah sarapah & 12. Ss \\
\hline
\end{tabular}




\begin{tabular}{|l|l|l|l|}
3 & Fungsi & $\begin{array}{l}\text { 1. Sebagai sarana magis untuk memanggil seseorang atau binatang yang berada di tempat jauh atau tidak } \\
\text { diketahui di mana berada; }\end{array}$ & $1 . \mathrm{Kr}$ \\
\hline & & 2. Sebagai sarana magis untuk menambah kesaktiannya; & $2 . \mathrm{Ks}$ \\
\hline & & 3. Sebagai sarana magis untuk memanggil seseorang yang berada di alam gaib; & 3. Mm \\
\hline & & 4. Sarana magis untuk menguna-gunai orang lain suapaya bertambah kasih; & $4 . \mathrm{Ps}$ \\
\hline & & 5. Sebagai sarana magis untuk menguna-gunai orang lain supaya orang itu dibenci orang; & $5 . \mathrm{PB}$ \\
\hline & & 6. Sebagai sarana magis untuk menguna-gunai orang lain supaya menjadi bungkam (tak berkutik); & $6 . \mathrm{Pm}$ \\
\hline & & 7. Sebagai sarana magis untuk mengobati orang lain agar sembuh dari penyakit yang dideritanya; & $7 . \mathrm{Pn}$ \\
\hline & & 9. Sebagai sarana magis untuk menguna-gunai siapa saja agar terpikat jatuh hati; & $8 . \mathrm{Pi}$ \\
\hline & 10. Sebagai sarana magis untuk meningkatkan pencapaian hasil kerja atau hasil usaha; & $9 . \mathrm{Pk}$ \\
\hline & 11. Sebagai sarana magis untuk menguna-gunai orang lain supaya menjadi tunduk tidak berkutik; & $10 . \mathrm{Pr}$ \\
\hline & 12. Sebagai sarana magis untuk mengusir hantu, iblis, setan, atau roh jahat yang mengganggu; & $11 . \mathrm{Pd}$ \\
\hline
\end{tabular}

\section{HASIL DAN PEMBAHASAN}

Dalam penelitian ini untuk menentukan bentuk fisik mantra Banjar peneliti merujuk pada teori bentuk fisik mantra Banjar sebagaimana yang dikutipkan Sulistiyowati dan Ganie (2013:43) bahwa mantra Banjar merujuk pada 2 pola bentuk, yakni pola bentuk mantra bebas dan pola bentuk mantra terikat.

\section{a). Mantra Banjar Bentuk Bebas}

Mantra Banjar dengan pola bentuk mantra bebas adalah mantra yang digubah tanpa rujukan konvensi bentuk sama sekali. Tidak ada rujukan jumlah kata dalam satu baris, dan jumlah baris dalam satu bait. Konvensi yang dirujuk hanya menyangkut pola persajakannya saja, yakni sajak awal, sajak dalam, dan sajak akhir. Posisi kata bersajak awal,dalam,dan akhir itu dapat terjadi dalam satu baris yang sama (bersajak horisontal) atau pada baris yang berbeda (bersajak vertikal pada satu bait yang sama). Bahkan, pada kasus yang ekstrim, perulangan bunyi sajaknya baru terjadi jika bait mantra Banjar dimaksud dibaca berulang kali (3,5, atau 7 kali) (seperti refren pada lirik lagu).

\section{b). Mantra Banjar Bentuk Terikat 1 \\ Dalam meneliti pola mantra}

Banjar bentuk mantra terikat 1,

peneliti menggunakan rujukan sebagaimana yang dikutipkan Sulistiyowati dan Ganie (2013:43), bahwa mantra Banjar bentuk terikat 1 terdiri atas :

(a). Baris Pembuka : tidak ada

(b). Baris Isi : berupa pantun (sampiran dan isi)

(c). Baris Penutup : tidak ada

c). Mantra Banjar Bentuk Terikat 2

Dalam meneliti pola mantra Banjar bentuk mantra terikat 1, peneliti menggunakan rujukan sebagaimana yang dikutipkan Sulistiyowati dan Ganie (2013:43), bahwa mantra Banjar bentuk terikat 2 terdiri atas :

(a). Baris Pembuka : lafadz bismillahirrahmannirrahiim

(b). Baris Isi : berupa pantun (sampiran dan isi)

(c). Baris Penutup : lafadz Barakat La Illahaa Illallah Muhammadarrasulullah

d). Mantra Banjar Bentuk Terikat 3 
Dalam meneliti pola mantra Banjar bentuk mantra terikat 3, peneliti menggunakan rujukan sebagaimana yang dikutipkan Sulistiyowati dan Ganie (2013:43), bahwa mantra Banjar bentuk terikat 3 terdiri atas :

(a). Baris Pembuka : lafadz bismillahirrahmannirrahiim

(b). Baris Isi : berupa puisi bebas

(c). Baris Penutup : tidak ada

e). Mantra Banjar Bentuk Terikat 4

Dalam meneliti pola mantra

Banjar bentuk mantra terikat 4, peneliti menggunakan rujukan sebagaimana yang dikutipkan Sulistiyowati dan Ganie (2013:43), bahwa mantra Banjar bentuk terikat 3 terdiri atas :

(a).Baris Pembuka : lafadz bismillahirrahmannirrahiim

(b). Baris Isi : berupa puisi bebas

(c).Baris Penutup : lafadz Barakat La

Illahaa

Illallah

Muhammadarrasulullah

Sejalan dengan Ganie dalam (Saberi, 2010: 18-19) yang mengklasifikasikan mantra Banjar kedalam $14 \mathrm{ragam} / \mathrm{jenis}$ yaitu : (a) Kariau (b) Kasumbi (c) Mamang (d) Pakasih (e) Pambanci Pambungkam (g) Panangkal (h) Panawar (i) Panulak (j) Papikat (k) Pikaras (1) Pirunduk (m) Sangga (n) Sumpah sarapah, peneliti dalam penelitian ini juga menggunakan rujukan tersebut, kecuali pada mantra Banjar jenis/ragam panangkal, panulak, dan sangga disini peneliti menggunakan rujukan dari Saberi (2010: 28) yang menggabungkan jenis/ragam mantra Banjar tersebut menjadi satu dengan nama panulak, karena hasil dari temuan peneliti bahwa jenis/ragam panangkal, panulak, dan sangga memiliki objek tujuan yang sama yaitu untuk menolak segala marabahaya yang bersifat kasat mata (nyata) bukan bersifat gaib, seperti bencana alam, maling, binatang buas, binatang penggigit, binatang penyengat racun yang ditaburkan orang di dalam makanan atau minuman. Berikut jenis/ragam mantra Banjar yang peneliti gunakan sebagai rujukan :

a. Kariau

b. Kasumbi

c. Mamang

d. Pakasih

e. Pambanci

f. Pambungkam

g. Panawar

h. Panulak

i. Papikat

j. Pikaras

k. Pirunduk

l. Sumpah sarapah

\section{Kesimpulan}

Berdasarkan hasil dari penelitian yang telah dipaparkan sebelumnya, maka perlu dikemukakan beberapa kesimpulan, diantaranya :

a. Ciri-ciri bentuk mantra Banjar yang dapat diinventarisasikan dalam penelitian ini ada 5 pola, yakni :

1. Pola mantra Banjar berbentuk puisi bebas (MBBB) sebanyak 8 buah

2. Pola mantra Banjar berbentuk terikat 1 (MBBT 1) sebanyak 6 buah

3. Pola mantra Banjar berbentuk terikat 2 (MBBT 2) sebanyak 6 buah

4. Pola mantra Banjar berbentuk terikat 3 (MBBT 3) sebanyak 5 buah 
5. Pola mantra Banjar berbentuk terikat 4 (MBBT 14) sebanyak 15 buah

b. Sistem pemberian nama jenis untuk mantra Banjar dilakukan oleh para pengubah mantra Banjar bukan berdasarkan pada bentuk fisik atau pada tafsiran makna secara keseluruhan melainkan berdasarkan pada fungsisosialnya di masyarakat. Penelitian ini berhasil menginventariskan 12 jenis mantra Banjar, yakni Kariau (4 buah), Kasumbi (4 buah), Mamang (3 buah), Pakasih (2 buah), Pambanci (2 buah), Pambungkam (1 buah), Panawar (5 buah), Panulak (2 buah), Papikat (5 buah), Pikaras (4 buah), Pirunduk (5 buah), Sumpah Sarapah (3 buah).

c. Ciri-ciri fungsi mantra Banjar di Kalimantan Selatan mempunyai hubungan yang signifikan dengan kebutuhan masnyarakat Banjar yang beraneka ragam. Kosa kata yang dipilih sebagai bahan dasar penggubahan mantra Banjar didasarkan pada tujuan fungsionalnya. Penelitian ini berhasil menginventariskan 12 buah fungsi mantra Banjar, yakni $K r$ (4 buah), $K s$ (4 buah), $M m$ (3 buah), $P s$ (2 buah), $P b$ (2 buah), $P m$ (1 buah), Pn (5 buah), $P l$ (2 buah), Pk (5 buah), Pr (4 buah), $P d$ (5 buah), $S s$ (3 buah).

\section{DAFTAR PUSTAKA}

Anwar, Desy. 2003. Kamus Lengkap Bahasa Indonesia. Surabaya: Amelia Surabaya.

Cahyo, Agus Dwi. EYD.Ejaan Yang Disempurnakan. 2011. Surabaya : Terbit Terang.
Effendi, Drs. Rustam 2011. Sastra Banjar Teori dan Interprestasi. Banjarmasin: Scripta Cendikia.

Hapip, Abdul Djebar. 2008. Kamus Banjar - Indonesia. Cetakan keenam. Banjarbaru: CV. Rahmat Hafiz Al Mubaraq.

Laelasari dan Nurlailah. 2006. Kamus Istilah Sastra. Cetakan kedua. Bandung: Penerbit Nuansa Aulia.

Saberi. 2010. Mantra Banjar, Analisis Bentuk, Fungsi, Makna, dan Penandanya. Tesis tidak diterbitkan. Banjarmasin: Program Studi Magister Pendidikan Bahasa dan Sastra Daerah Universitas Lambung Mangkurat.

Sugiarto, Eko. 2015.Mengenal Sastra Lama. Banjarmasin: Penerbit Andi.

Sulistyowati, Endang dan Ganie, Tajuddin Noor. 2010. Sastra Banjar Genre Lama Bercorak Puisi. Cetakan kedua. Banjarmasin: Tuas Media

Sunarti, dkk. 1978. Sastra Lisan Banjar. Jakarta: Pusat Bahasa.

Suroso,dkk. 2009. Kritik Sastra Teori, Metodologi dan Aplikasi. 2009. Yogyakarta: Elmatera Publisihing.

Sehandi, Yohanes. 2016. Mengenal 25 Teori Sastra. Cetakan Kedua. Yogyakarta: Penerbit Ombak. 